\title{
COMPARISON OF A-SMGCS REQUIREMENTS WITH OBSERVED PERFORMANCE OF AN INTEGRATED AIRPORT CNS SYSTEM
}

\author{
Steven D. Young, NASA-Langley Research Center
}

\begin{abstract}
The International Civil Aviation Organization (ICAO) has recently drafted a reference document describing the operational requirements for Advanced Surface Movement Guidance and Control Systems (A-SMGCS) [1]. During the summer of 1997, NASA, the FAA, industry, and academia partners demonstrated a holistic system approach that has the potential to meet many of the proposed A-SMGCS requirements. An assessment of the field tested system and data resulting from the field testing is presented to determine its compliance with A-SMGCS requirements. In those areas where compliance was not demonstrated, a recommendation is presented suggesting further research or a modification of the system architecture.
\end{abstract}

\section{Introduction}

Advanced Surface Movement Guidance and Control Systems (A-SMGCS) is the term used by ICAO to describe a modular system that is needed in the future to support safe, orderly, and expeditious movement of aircraft and vehicles on the airport surface under all circumstances with respect to visibility, traffic density, and complexity of the airport layout. Operational requirements have been written that are technology-independent and provide guidelines for the analysis and development of implementation-specific requirements. The need for A-SMGCS has arisen due to the rising number of surface incidents, the increasing complexity of airports, the increasing number of operations, and the desire to maintain capacity in all weather conditions.
Concurrent with ICAO's development of these requirements, focused research at NASA has resulted in a holistic systems approach to supporting low visibility airport surface operations while maintaining capacity. Milestones of this research have included several flight simulation studies and two flight test activities. The most recent flight testing occurred during the summer of 1997 at the Hartsfield-Atlanta International Airport (ATL). NASA, the FAA, industry, and academia partners demonstrated, at ATL, a prototype system that not only met many of the goals of the research program, but also showed its potential for meeting the proposed A-SMGCS requirements. The prototype communication, navigation, and surveillance (CNS) system consisted of both ground-based and airborne components with digital data links and radio communications integrating the two.

In the following sections, an assessment of this field tested system and data resulting from the field testing is presented, along with the A-SMGCS requirements. Compliance is shown where appropriate. In the final section of the paper, for those areas where compliance was not demonstrated, a recommendation is presented suggesting further research or justifying a modification of the system design or the proposed requirement.

\section{A-SMGCS Requirements}

The current SMGCS design and implementation is based on procedures and enhanced lighting that is not always capable of supporting desired capacity levels under low visibility conditions [1]. A-SMGCS requirements have been drafted such that 
regardless of the visibility conditions, aircraft operations can be safely supported at high levels of capacity. The requirements were written to be technology-independent and to allow airport operators to implement specific A-SMGCS functions depending on local circumstances or needs.

The A-SMGCS operational concept supports the expected growth in airport operations while minimizing delay and pilot/controller workload. It supports the sharing of information among the users (e.g. pilots, controllers, vehicle drivers) and supports provisions for improved guidance via both visual aids and electronic means. Complex traffic flows will require an A-SMGCS to function as a surface management system with responsibilities to provide for the planning of surface movements and to be a part of the global CNS/ATM concept which supports "gate-to-gate" operations.

In order to support safe efficient gateto-gate operations, A-SMGCS must provide suitable facilities for surveillance, routing, guidance, and control of all surface movements (figure 1). The requirements for these four primary functions will depend on the visibility condition (VC), traffic density (TD), and airport layout (AL). The most stringent of these are: VC 4 (visibility less than $75 \mathrm{~m}$ ); TD heavy (greater than 25 take-offs or landings per runway per hour); and AL complex (an airport with more than one runway).

\section{Surveillance}

The A-SMGCS definition of surveillance is a function that captures identification and positional information on aircraft, vehicles, and objects within a specified airport area. Current SMGCS surveillance procedures are based on the "see and be seen" principal to maintain separation on the airport surface. Advanced methods of surveillance are

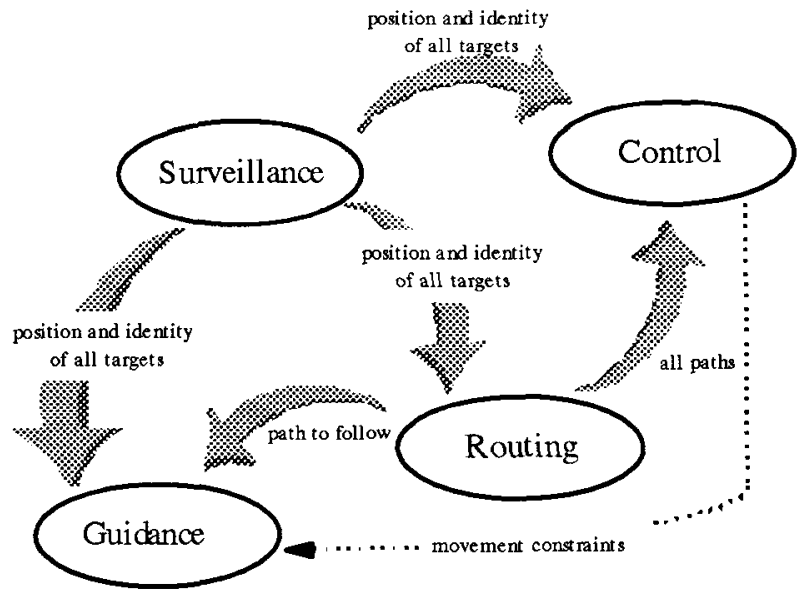

Figure 1. A-SMGCS Functional Dependencies.

required to ensure safe separations during periods of high density and low visibility. In these conditions, "see and be seen" procedures must be supplemented. Specific A-SMGCS requirements for the surveillance function are':

S.1 Capable of providing accurate position information on all surface movements.

S.2 Capable of identifying and labelling all surface movements.

S.3 Cope with both moving and static aircraft and vehicles.

S.4 Capable of updating data required by the guidance and control functions.

S.5 Immune to adverse weather and topographical conditions.

S.6 Provide for health monitoring of surveillance equipment.

S.7 Provide control authorities with surveillance data.

S.8 Provided to an altitude to cover missed approaches and helicopter operations.

S.9 Provided to cover aircraft on approach out to an appropriate distance.

S.10 Support a seamless transition to terminal area surveillance.

${ }^{1}$ For brevity, the author has paraphrased some of the ASMGCS requirements. 
S.11 Detect runway incursions and incursions into unauthorized areas.

S.12 Detect deviations from assigned route.

S.13 Support the control function in detecting conflicts.

\section{Routing}

The routing function of A-SMGCS is defined as the planning and assignment of a route to individual aircraft and vehicles to provide safe, expeditious and efficient movement from its current position to its intended position. Currently taxi routes are provided via radio communications. On request, ATC provides flight crews with the route to follow using a standard phraseology. The route is then read-back by the pilot to confirm receipt and understanding of the radio transmission. Routes are generated by ATC based on the activity that can be seen from the tower cab and a mental picture of airport traffic and airport layout. Specific A-SMGCS requirements for the routing function are:

R.1 Enable a route to be designated for all aircraft and vehicles.

R.2 Allow for a change of destination at any time.

R.3 Allow for a change of route to the same destination at any time.

R.4 Capable of meeting the needs of dense traffic patterns at complex airports.

R.5 Shall not constrain the pilot's choice of runway exit after landing.

R.6 Support minimum taxi distances for any operational configuration.

R.7 Interact with the control function to minimize conflicts at intersections.

R.8 Responsive to operational changes (e.g. closed taxiways or temporary hazards).

R.9 Support standard terminology or symbology.
R.10 Provide routes in a timely manner on request from all users.

R.11 Provide a means of validating routes.

R.12 Provide the control authority with recommended routes for designation.

R.13 In automatic mode, designate and assign routes.

R.14 In automatic mode, support manual intervention by the control authority.

\section{Guidance}

The guidance function of A-SMGCS is defined as the necessary advisory information, provided in a continuous unambiguous reliable manner, such that pilots and vehicle operators can steer their aircraft or vehicle along the assigned route while maintaining an appropriate velocity. In today's environment, guidance is provided to flight crews via visual aids during airport surface operations. Pilots navigate on the surface by referring to painted markings (e.g. centerlines), signage, and in-pavement lights. Airport charts are used for a more global reference. Occasionally, progressive taxi instructions are issued by ATC to aid pilots. ASMGCS requirements for the guidance function are:

G.1 Provide guidance for all possible route assignments.

G.2 Provide clear, unambiguous, indications to pilots and vehicle drivers such that they can follow their assigned route.

G.3 Enable pilots and vehicle drivers to maintain awareness of their position along the assigned route.

G.4 Capable of accepting a change of route at any time.

G.5 Capable of indicating restricted areas of the airport surface.

G.6 Allow for monitoring of the operational status of all guidance aids. 


\section{Control}

The control function of A-SMGCS is defined as the application of measures to prevent collisions, runway incursions, and to ensure safe, expeditious and efficient movement on the airport surface. The control function is typically performed by allocating responsibilities to both pilots and controllers. The pilot performs "see and avoid", while the controller issues movement constraints (e.g. hold-short instructions) to reduce the likelihood of conflict. A-SMGCS requirements for the control function are:

C.1 Capable of supporting the maximum movement rate at any time.

C.2 Capable of supporting the planning of requested movements for up to one hour.

C.3 Detect conflicts and provide resolutions on designated routes in a timely manner.

C. 4 Provide for required separation minima and generate alerts when separation falls below the minima.

C.5 Provide alerts for intrusions to runways/taxiways and activate protection devices (e.g. alarms).

C.6 Provide alerts for intrusions to critical or sensitive areas (e.g. radio navigation aids).

C.7 Provide alerts for intrusions to emergency areas.

C.8 Keep pilots, vehicle drivers, and controllers in the decision loop.

C.9 Support prioritizing control activities.

C.10 Sequencing of aircraft to ensure minimum delay and maximum utilization of airport capacity.

C.11 Capable of segregating support and maintainence vehicle operations.

C.12 Separate movements from obstacles, secure areas, and restricted areas.
C.13 Provide alerts when an aircraft or vehicle is predicted to enter a restricted area.

\section{C.14 Provide deviation alerts.}

\section{System Requirements}

Also described in [1] are several systemlevel requirements of A-SMGCS. In general, they allude to the operational environment envisioned for A-SMGCS. For example, the ASMGCS should support all aircraft and vehicles types as well as all weather and visibility conditions. The system should be implementable at any airport. The system should support strategic planning of operations in advance. Human-machine interface requirements are also described in general.

\section{LVLASO $^{2}$ CNS System Description}

The LVLASO CNS system has been specifically designed by NASA to support safe efficient airport operations in low visibility conditions. Further, it has primarily been targeted for commercial transport application and large airport facilities. This goal is very close to the operational environment that poses the most stringent requirements on an ASMGCS implementation (see page 2). Because this research compliments the goals of ASMGCS, and a prototype system has been fielded, it becomes possible to assess compliance and to assess the validity of the proposed requirements against the field tested system.

The system implemented at ATL (figure 2) consisted of several subsystems that were integrated into a CNS system [2]. The system included:

- A ground-based surveillance system that provided surveillance data to ATC and to any equipped aircraft/vehicle via data link.

\footnotetext{
${ }^{2}$ LVLASO is the Low Visibility Landing and Surface Operations focused research program.
} 


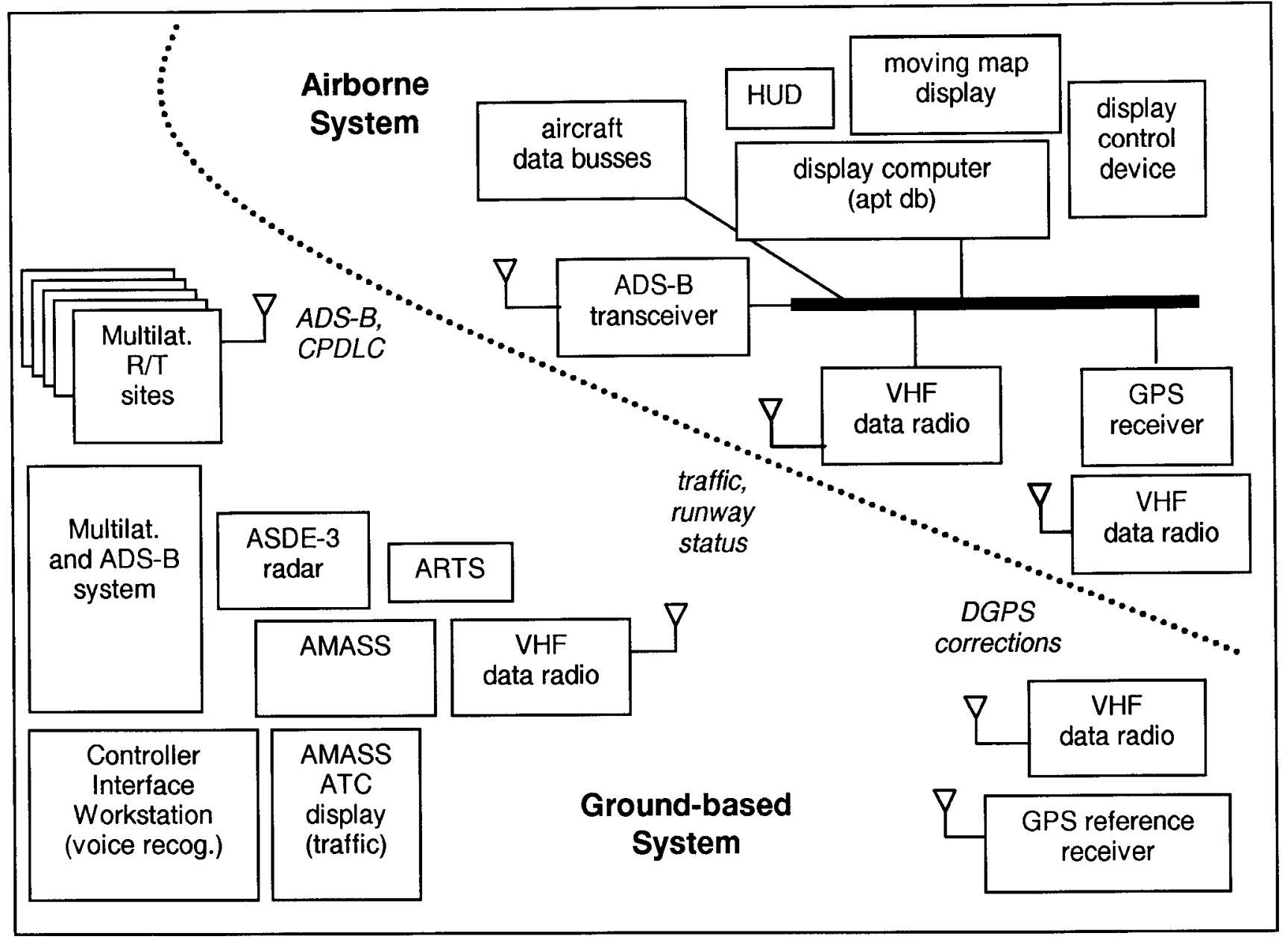

Figure 2. LVLASO CNS System Architecture.

- Flight deck displays that utilized DGPS and an onboard airport database to provide supplemental guidance, surveillance, routing, and control information to the flight crew during surface operations.

- Controller displays that provided ATC a supplemental means of surveillance as well as alerts of route deviation, incursions, and conflicts.

- Controller-pilot data link communications (CPDLC) that allowed ATC to issue instructions via an independent link in parallel with the normal voice channel, and to be alerted of pilot deviations.

\section{Compliance Tables}

The information contained in the following tables is intended to describe how the LVLASO CNS system design complies with the
A-SMGCS requirements as they are currently drafted. Although the airborne portion of the system was only implemented on a single aircraft at ATL, the compliance tables assume the envisioned system were implemented on all aircraft/vehicles. Also, the compliance tables are generated for the most stringent A-SMGCS case: low visibility (less than $75 \mathrm{~m}$ ); heavy traffic density; and a complex airport.

In terms of surveillance, many operational requirements of A-SMGCS were demonstrated during the ATL trials. Adverse weather (S.5) is not expected to affect the performance of ADS-B or multilateration. Although radar performance has been shown to deteriorate in periods of heavy rain, the ASDE3 radar was specifically designed to minimize weather effects. Transitioning to terminal radar surveillance (S.10) was not demonstrated at ATL. However, it is a design requirement for the FAA's surface surveillance system and will be implemented in the next prototype. 
Table 1. Surveillance Requirements

\begin{tabular}{|l|l|l|}
\hline Req't & Comply & Method/Note \\
\hline S.1 & Yes & $\begin{array}{l}\text { Fusion of radar, } \\
\text { multilateration, and ADS-B } \\
\text { reports available via data link } \\
\text { broadcast }\end{array}$ \\
\hline S.2 & Yes & $\begin{array}{l}\text { Identification requires } \\
\text { transponder }\end{array}$ \\
\hline S.3 & Yes & $\begin{array}{l}\text { Surveillance is independent of } \\
\text { aircraft/vehicle state of motion }\end{array}$ \\
\hline S.4 & Yes & $\begin{array}{l}\text { Provided to both ATC and } \\
\text { flight deck displays to support } \\
\text { "see and avoid" }\end{array}$ \\
\hline S.5 & $*$ & $\begin{array}{l}\text { System not tested in adverse } \\
\text { weather }\end{array}$ \\
\hline S.6 & Yes & $\begin{array}{l}\text { Alerts of system failures are } \\
\text { generated }\end{array}$ \\
\hline S.7 & Yes & $\begin{array}{l}\text { Surveillance data depicted on } \\
\text { multiple controller displays }\end{array}$ \\
\hline S.8 & Yes & $\begin{array}{l}\text { Radar covers up to 500', } \\
\text { multilateration to 300', ADS-B } \\
\text { limit not measured but }>\text { 500' }\end{array}$ \\
\hline S.9 & Yes & Only radar is marginal \\
\hline S.10 & $*$ & Not tested \\
\hline S.11 & Yes & AMASS functionality \\
\hline S.12 & Yes & $\begin{array}{l}\text { Performed onboard with } \\
\text { deviation alert data linked to } \\
\text { ATC via CPDLC }\end{array}$ \\
\hline S.13 & Yes & AMASS functionality \\
\hline
\end{tabular}

Selected performance requirements for the surveillance system are shown in Table 2 along with the observed performance achieved at ATL.

The surveillance system employed at ATL was not designed to cover the ramp areas of the airport. To fully implement A-SMGCS, this would need to be addressed. Radar is not recommended for ramp coverage; however, either multilateration (with appropriate siting) and/or ADS-B (which requires transponder equipage) can provide this coverage. Approach coverage was not demonstrated; however, this

\footnotetext{
3 "Yes" indicates compliance has been demonstrated in the field, "No" indicates the architecture will not support this requirement, and "*" indicates the architecture can support the requirement, although it was not necessarily implemented or validated in the field.
}

can be achieved by integrating with the approach radar as the two coverage areas were shown to overlap at ATL. During the period of testing, no more than 47 aircraft/vehicles were observed on the movement area at any one time. It is anticipated that more than 100 targets can be accommodated by a surveillance system architecture as employed at ATL.

Table 2. Surveillance Performance

\begin{tabular}{|c|c|c|}
\hline Requirement & $\begin{array}{c}\text { A-SMGCS } \\
\text { req't }\end{array}$ & $\begin{array}{c}\text { LVLASO } \\
\text { observed }\end{array}$ \\
\hline $\begin{array}{l}\text { Surface coverage } \\
\text { area }\end{array}$ & $\begin{array}{l}\text { Movement } \\
\text { area, ramp }\end{array}$ & Movement area \\
\hline Altitude coverage & $500^{\prime} \mathrm{AGL}$ & $\begin{array}{c}1000^{\prime} \text { (mlat.) } \\
>1000^{\prime} \text { (ADS-B) } \\
500^{\prime} \text { (radar) }\end{array}$ \\
\hline $\begin{array}{l}\text { Approach } \\
\text { coverage }\end{array}$ & $10 \mathrm{~nm}$ & $\begin{array}{l}\text { coverage overlaps } \\
\text { with apprch. radar }\end{array}$ \\
\hline $\begin{array}{l}\mathrm{A} / \mathrm{C} \text { on movement } \\
\text { area }\end{array}$ & 100 & $\begin{array}{c}47 \\
\text { (max. observed) }\end{array}$ \\
\hline $\begin{array}{l}\text { Horizontal } \\
\text { accuracy }(95 \%)\end{array}$ & $10 \mathrm{~m}$ & $\begin{array}{c}6.9 \mathrm{~m} \text { (mlat.) } \\
1.4 \mathrm{~m} \text { (ADS-B) } \\
6.4 \mathrm{~m} \text { (radar) } \\
\end{array}$ \\
\hline $\begin{array}{l}\text { Update rate } \\
\text { (at } 98 \% \text { update } \\
\text { success rate) }\end{array}$ & $1 \mathrm{~Hz}$ & $\begin{array}{c}0.25 \mathrm{~Hz} \text { (mlat.) } \\
1.05 \mathrm{~Hz} \text { (ADS-B) } \\
0.95 \mathrm{~Hz} \text { (radar) }\end{array}$ \\
\hline Latency & $1 \mathrm{sec}$ & $\begin{array}{l}0.4 \mathrm{sec} \text { (mlat.) } \\
0.1 \mathrm{sec} \text { (radar) }\end{array}$ \\
\hline
\end{tabular}

Finally, the latency listed is that observed by the ATC user. The latency observed in the flight deck was as high as two seconds due to the processing algorithms employed onboard. It is expected that the one second latency requirement can be achieved in the flight deck using a more efficient algorithm for displaying traffic updates.

In terms of routing, many operational requirements of A-SMGCS were demonstrated during the ATL trials. Generating routes that are minimum distance (R.6) is an automation function that can be implemented within the LVLASO system infrastructure either onboard or at the controller workstation. This requires real-time surveillance data, desired destination, and an airport database. All of these are 
available at either location in the system.

Table 3. Routing Requirements

\begin{tabular}{|l|l|l|}
\hline Req't & Comply & Method/Note \\
\hline R.1 & Yes & Voice + CPDLC \\
\hline R.2 & Yes & Voice + CPDLC \\
\hline R.3 & Yes & Voice + CPDLC \\
\hline R.4 & Yes & $\begin{array}{l}\text { CPDLC will reduce the amount } \\
\text { of voice congestion }\end{array}$ \\
\hline R.5 & Yes & $\begin{array}{l}\text { Arrival taxi routes requested } \\
\text { after runway exit }\end{array}$ \\
\hline R.6 & $*$ & Not tested \\
\hline R.7 & Yes & $\begin{array}{l}\text { Routes for all aircraft can be } \\
\text { depicted on controller display; } \\
\text { route deviation alerts generated }\end{array}$ \\
\hline R.8 & $*$ & Not tested \\
\hline R.9 & Yes & $\begin{array}{l}\text { ATC/pilot uses standard } \\
\text { phraseology; routes depicted to } \\
\text { pilots similar to enroute ND }\end{array}$ \\
\hline R.10 & Yes & Voice + CPDLC \\
\hline R.11 & Yes & $\begin{array}{l}\text { On receipt via CPDLC, } \\
\text { airborne system checks route } \\
\text { for validity }\end{array}$ \\
\hline R.12 & $*$ & Not tested \\
\hline R.13 & $*$ & Not tested \\
\hline R.14 & $*$ & Not tested \\
\hline
\end{tabular}

Responding to operational changes (R.8) is supported but was not tested/validated at ATL. Providing ATC with recommended routes (R.12) can be implemented within LVLASO's controller workstation. These can be standard routes that are stored and provided on request, or these can be determined dynamically based on current conditions and specified constraints (e.g. closed taxiways, traffic bottlenecks, or gate assignment). This was not demonstrated at ATL but is being considered for implementation and evaluation. Automatic modes of providing route instructions (R.13 and R.14) were not implemented or demonstrated at ATL. The LVLASO CNS system architecture could support this concept.

The performance requirement for the routing system that is relevant to the ATL LVLASO system is listed in Table 4. The other routing performance requirements listed in [1] relate to automatically generating routes which was not done at ATL.

Table 4. Routing Performance

\begin{tabular}{|l|c|c|}
\hline Requirement & $\begin{array}{c}\text { A-SMGCS } \\
\text { req't }\end{array}$ & $\begin{array}{c}\text { LVLASO } \\
\text { observed }\end{array}$ \\
\hline $\begin{array}{l}\text { Time to transmit } \\
\text { route to aircraft }\end{array}$ & $1 \mathrm{sec}$ & $0.5 \mathrm{sec}$ \\
\hline
\end{tabular}

Table 5. Guidance Requirements

\begin{tabular}{|l|l|l|}
\hline Req't & Comply & Method/Note \\
\hline G.1 & Yes & $\begin{array}{l}\text { Visual aids + ATC verbal + } \\
\text { HUD + map display + DGPS }\end{array}$ \\
\hline G.2 & Yes & HUD + map display + CPDLC \\
\hline G.3 & Yes & HUD + map display + DGPS \\
\hline G.4 & Yes & Voice + CPDLC \\
\hline G.5 & Yes & Map display \\
\hline G.6 & Yes & $\begin{array}{l}\text { Alerts of guidance display } \\
\text { system failures were generated }\end{array}$ \\
\hline
\end{tabular}

As shown in Table 5, the operational requirements for the guidance function were met at ATL. The relevant A-SMGCS performance requirement for the guidance function is shown in Table 6 with the observed performance achieved at ATL. Compliance with accuracy requirements suggested for the gate areas cannot be shown as gate operations were not done during the ATL testing.

Table 6. Guidance Performance

\begin{tabular}{|l|c|c|}
\hline $\begin{array}{l}\text { Requirement } \\
\text { (Airport Code E) }\end{array}$ & $\begin{array}{c}\text { A-SMGCS } \\
\text { req't }\end{array}$ & $\begin{array}{c}\text { LVLASO } \\
\text { observed }\end{array}$ \\
\hline $\begin{array}{l}\text { Horizontal accuracy } \\
\text { (taxiway) }\end{array}$ & $\begin{array}{l}2.2 \mathrm{~m} \\
(95 \%)\end{array}$ & $\begin{array}{l}1.3 \mathrm{~m} \\
(95 \%)\end{array}$ \\
\hline
\end{tabular}

While the DGPS/INS navigation system employed on the B-757 performed well at ATL, it remains unclear whether the A-SMGCS requirements for low visibility gate operations can be achieved with this technology (i.e. DGPS). An alternate means of guidance may 
be necessary in these areas if high movement rates are expected to be maintained in low visibility.

Table 7. Control Requirements

\begin{tabular}{|l|l|l|}
\hline Req't & Comply & Method/Note \\
\hline C.1 & $*$ & Not tested \\
\hline C.2 & $*$ & Not tested \\
\hline C. 3 & $*$ & Not tested \\
\hline C.4 & $*$ & Not tested \\
\hline C.5 & Yes & AMASS functionality \\
\hline C.6 & $*$ & Not tested \\
\hline C. 7 & $*$ & Not tested \\
\hline C.8 & Yes & Information is advisory only \\
\hline C. 9 & Yes & ATC discretion \\
\hline C.10 & $*$ & Not tested \\
\hline C.11 & $*$ & Not tested \\
\hline C.12 & $*$ & Not tested \\
\hline C.13 & $*$ & Not tested \\
\hline C.14 & Yes & $\begin{array}{l}\text { Onboard system detected } \\
\text { deviations and alerted ATC }\end{array}$ \\
\hline
\end{tabular}

Many of the A-SMGCS operational requirements for the control function were not specifically tested at ATL (Table 7). The controller tools tested at ATL provided supplemental means for ATC to maintain awareness of traffic positions and to communicate with pilots in all weather conditions. These augmentations should allow ATC to support a higher movement rate in any visibility (C.1). In the LVLASO CNS system concept, resolving conflicts (C.3) and assuring separation (C.4) remains the responsibility of ATC as is currently done. Many of the automation functions suggested by A-SMGCS to aid controllers (C.10 to C.13) were not implemented at ATL.

The LVLASO control function was designed to minimize the impact on normal ATC procedures. Surveillance data is displayed to be used as needed to supplement visual acquisition. Voice recognition is used to capture instructions and forward them to pilots to reinforce the verbal radio transmissions and avoid misunderstandings/miscommunications.
This approach does not inhibit the architecture from supporting the automation functions suggested by A-SMGCS if they are deemed necessary.

\section{Summary}

The LVLASO CNS system concept is based primarily on two theories:

- Current procedures, visual aids, radio communications, and human performance enable safe airport surface operations at near peak flow rates in conditions of good visibility.

- In conditions of poor visibility, safe airport surface operations can be maintained at near peak flow rates if radio communications and the limited visual cues are supplemented, or reinforced, using technological approaches to surveillance, routing, guidance, and control functions. The application of these technologies can be accomplished in such a way to minimize the impact on current procedures both in the flight deck and in the ATC tower. Information provided by the new technologies is done so in a natural manner that permits it to be used as needed.

The primary difference between the LVLASO system approach and A-SMGCS is in the area of automation. The LVLASO approach does not suggest automating any function at this time over and above what current procedures require. While A-SMGCS requirements for automation (e.g. automatic route generation/transmission, planning for the control of surface movements in advance, and generating minimum distance routes) will most likely improve efficiency, it is not clear that they will improve capacity over and above what current clear weather procedures allow.

One example of automation that the ATL system did support was the automatic alerting of ATC of a route deviation. This is necessary to support current operational 
procedures in the tower. If visual conditions do not allow ATC to observe a deviation from a the tower cab, an indication must be provided to ATC to avoid a potential conflict.

The ATL system did not address required A-SMGCS functionality (surveillance, guidance, routing, and control) in the ramp area. This is being addressed as part of the ongoing research. Surveillance approaches being considered are ADS-B, multilateration, and ground loops. Additions to the airport geographic database along with enhanced DGPS/INS may support the guidance function. Routing and control augmentations will be addressed with respect to current ramp control procedures/systems.

Finally, required levels of integrity, continuity, and availability were not achieved by all components of the field-tested system. This is directly related to the maturity of the specific technologies employed. Components that adhered to established standards, or were certified, (e.g. the data links, the DGPS subsystem, and the flight deck displays) rarely failed or were unavailable (much less than $1 \%$ of the total test time) [2]. On the other hand, components/functions that were less mature (e.g. multilateration, surveillance sensor data fusion, and voice recognition), require further work to ensure adequate levels of availability, continuity, and integrity for full deployment of this concept.

\section{Conclusion}

This paper has shown that even in the most stringent conditions of visibility, traffic density, and airport complexity, the LVLASO CNS system architecture can provide for the primary A-SMGCS functions without requiring enhanced visual aids (e.g. lighting) or significant procedural changes. It does require additional equipage both in the tower, and in any aircraft and/or vehicles operating on the airport surface (GPS, data link, and display augmentations).
Future work will consider A-SMGCSrequired automation functions and ramp operations that have not been addressed to date by the LVLASO research team.

\section{References}

[1] Draft Manual of Advanced Surface Movement Guidance and Control Systems (A-SMGCS), 16th Meeting of the International Civil Aviation Organization's All Weather Operations Panel, Montreal, Canada, June 1997.

[2] Young, S., and Jones, D., Flight Testing of an Airport Surface Movement Guidance, Navigation, and Control System, Proceedings of the Institute of Navigation's National Technical Meeting, January 21-23, 1998. 